\title{
Effectiveness of a national reimbursement policy and accompanying media attention on use of cessation treatment and on smoking cessation: a real-world study in the Netherlands
}

Citation for published version (APA):

Nagelhout, G. E., Willemsen, M. C., van den Putte, B., de Vries, H., Willems, R. A., \& Segaar, D. (2015). Effectiveness of a national reimbursement policy and accompanying media attention on use of cessation treatment and on smoking cessation: a real-world study in the Netherlands. Tobacco Control, 24(5), 455461. https://doi.org/10.1136/tobaccocontrol-2013-051430

Document status and date:

Published: 01/01/2015

DOI:

10.1136/tobaccocontrol-2013-051430

Document Version:

Publisher's PDF, also known as Version of record

Document license:

Taverne

Please check the document version of this publication:

- A submitted manuscript is the version of the article upon submission and before peer-review. There can be important differences between the submitted version and the official published version of record. People interested in the research are advised to contact the author for the final version of the publication, or visit the DOI to the publisher's website.

- The final author version and the galley proof are versions of the publication after peer review.

- The final published version features the final layout of the paper including the volume, issue and page numbers.

Link to publication

\footnotetext{
General rights rights.

- You may freely distribute the URL identifying the publication in the public portal. please follow below link for the End User Agreement:

www.umlib.nl/taverne-license

Take down policy

If you believe that this document breaches copyright please contact us at:

repository@maastrichtuniversity.nl

providing details and we will investigate your claim.
}

Copyright and moral rights for the publications made accessible in the public portal are retained by the authors and/or other copyright owners and it is a condition of accessing publications that users recognise and abide by the legal requirements associated with these

- Users may download and print one copy of any publication from the public portal for the purpose of private study or research.

- You may not further distribute the material or use it for any profit-making activity or commercial gain

If the publication is distributed under the terms of Article 25fa of the Dutch Copyright Act, indicated by the "Taverne" license above,

Download date: 26 Apr. 2023 


\title{
Effectiveness of a national reimbursement policy and accompanying media attention on use of cessation treatment and on smoking cessation: a real-world study in the Netherlands
}

\author{
Gera E Nagelhout, ${ }^{1,2}$ Marc C Willemsen, ${ }^{1,2}$ Bas van den Putte, ${ }^{3,4}$ Hein de Vries, ${ }^{1}$ \\ Roy A Willems, ${ }^{5}$ Dewi Segaar ${ }^{2}$
}

${ }^{1}$ Department of Health Promotion, Maastricht University (CAPHRI), Maastricht, The Netherlands ${ }^{2}$ Alliance Smokefree Holland The Hague, The Netherlands ${ }^{3}$ Department of Communication, University of Amsterdam (ASCOR), Amsterdam, The Netherlands ${ }^{4}$ Trimbos Institute, Netherlands Institute for Mental Health and Addiction, Utrecht, The Netherlands

${ }^{5}$ School of Psychology, Open University of the Netherlands, Heerlen, The Netherlands

\section{Correspondence to}

Dr Gera Nagelhout, Alliantie Nederland Rookvrij,

Eisenhowerlaan 108, The Hague $2517 \mathrm{KL}$, The Netherlands; Gera. Nagelhout@alliantieNR.nl

Received 4 November 2013 Revised 9 April 2014 Accepted 22 April 2014 Published Online First 19 May 2014

\section{CrossMark}

\author{
To cite: Nagelhout GE, \\ Willemsen MC, van den \\ Putte $\mathrm{B}$, et al. Tob Control
} 2015;24:455-461.

\begin{abstract}
Background In 2011, the Netherlands implemented a national policy that ensured that health insurance companies reimbursed behavioural counselling for smoking cessation or the combination of behavioural counselling with pharmacological therapy.

Objective To examine the real-world impact of a national reimbursement policy and accompanying media attention on use of cessation treatment and on smoking cessation.

Methods We used a four-wave longitudinal survey among 2763 adult smokers that started in September 2010 and was repeated at approximately 3 month intervals until June 2011. Two survey waves were conducted before the implementation of the policy and two survey waves after.

Findings There were significant increases in quit attempts (among moderate-to-heavy smokers) and in quit success (among all smokers) following the implementation of the reimbursement policy and the media attention. Use of behavioural counselling did not increase, while use of pharmacological therapy without behavioural counselling (unreimbursed treatment) increased among moderate-to-heavy smokers. Attention to media about the reimbursement was significantly associated with more quit attempts and more quit success. Awareness of the policy was significantly associated with more use of reimbursed treatment among all smokers, while attention to the media coverage was only significantly associated with more use of reimbursed treatment among moderate-to-heavy smokers. Awareness/attention variables were not significantly associated with use of unreimbursed treatment.

Conclusions It seems that a national reimbursement policy for smoking cessation treatment that is accompanied by media attention can increase cessation. Our findings suggest that this increase can (partly) be ascribed to the media attention that accompanied the policy implementation.
\end{abstract}

\section{INTRODUCTION}

The Framework Convention on Tobacco Control is the first international treaty in the domain of public health. ${ }^{1}$ Article 14 of the Framework Convention on Tobacco Control states that parties to the treaty shall take effective measures to promote smoking cessation and should facilitate accessibility and affordability of treatment for tobacco dependence. In the guidelines of Article 14, countries are urged to make efficacious cessation treatment available, where possible free of charge or at an affordable cost. $^{2}$ A recent review concluded that financial reimbursement of smoking cessation treatment can increase the use of nicotine replacement therapy, prescription medications and behavioural counselling and can stimulate smoking cessation attempts and success. ${ }^{3}$ However, because this evidence comes from experimental studies conducted under controlled research conditions, this is less informative about the real-world effectiveness of reimbursing cessation treatment. The current study examines whether a national reimbursement policy increased the use of cessation treatment and stimulated smoking cessation in the general population of smokers.

Previous studies about the real-world effectiveness of national reimbursement policies for smoking cessation treatment have emerged mainly from the UK. The UK National Health Service Stop Smoking Services have offered free of charge behavioural support and medications for smoking cessation for more than 10 years. $^{4}$ Evaluation studies have focused on changes in use of the services when they were already implemented, ${ }^{4} 5$ regional and sociodemographic variations in use ${ }^{6-8}$ and the real-world effectiveness of the received cessation treatment. ${ }^{9} 10$ However, additional studies are needed that compare the situation before and after countries implement a national reimbursement policy.

The Netherlands implemented a national policy for reimbursement of smoking cessation treatment in January 2011. Each smoker was eligible for full reimbursement of one smoking cessation programme per year. A smoking cessation programme consisted of multisession evidence-based behavioural counselling (group, face-to-face or telephonic counselling) and, if required, pharmacological therapy (nicotine replacement therapy or prescription medications). Pharmacological therapy was only reimbursed when smokers also participated in behavioural counselling. The Netherlands had a national quitline that offered multisession evidence-based behavioural counselling and, thus, all smokers in the Netherlands had access to reimbursable cessation treatment. ${ }^{11}$ The reimbursement was paid only after spending the mandatory deductible of $€ 170$ per year for any healthcare costs. This means that smokers were only fully reimbursed when they had completed their deductible. Smokers could get the reimbursement by claiming 
this from their health insurance company. In the Netherlands, health insurance coverage is statutory and only $1 \%$ of the population is uninsured. ${ }^{12}$

The introduction of the new reimbursement policy in the Netherlands was accompanied by media attention. Most notably, a media campaign was created by the Dutch Expert Centre on Tobacco Control (STIVORO) and the Dutch Cancer Society to communicate to the public that smoking cessation treatment will be reimbursed from 2011. The campaign was funded by the Netherlands Organization for Health Research and Development (ZonMw) and the Dutch Cancer Society, it ran from December 2010 to January 2011 and campaign exposure among smokers was around $80 \%{ }^{13}$ The campaign message was that it is possible to 'really' quit smoking if you use the 'right' cessation treatment (nicotine replacement therapy, prescription medications and behavioural counselling). It was expected that this campaign message would help increase the use of reimbursed smoking cessation treatment and the number of quit attempts. Other media attention included commercial advertisements from pharmaceutical companies and information about the policy in news stories that were published in several media.

Smoking prevalence in the Netherlands has fluctuated between $27 \%$ and $28 \%$ from 2004 to 2010 , with higher levels of smoking among lower educated groups. ${ }^{14}$ In 2010, pharmacological therapy was the most commonly used smoking cessation treatment in the Netherlands but few smokers used a combination of pharmacological therapy and behavioural counselling. ${ }^{15}$ The Dutch clinical guideline for the treatment of tobacco addiction recommends pharmacological therapy for moderate-to-heavy smokers, that is, those who smoke 10 or more cigarettes per day (CPD), in addition to behavioural counselling. ${ }^{16}$ In concordance with this recommendation, a recent study showed that Dutch moderate-to-heavy smokers $\mathbf{( 7 1 \%}$ of all smokers in the Netherlands ${ }^{17}$ ) are more likely to receive advice from their general practitioner to use pharmacological therapy compared with light smokers. ${ }^{17}$ Therefore, it is important to examine effects separately for light and moderate-to-heavy smokers.

This longitudinal study examined whether there was an increase in smoking cessation and use of treatment after the implementation of the policy and the media coverage in the Netherlands. Furthermore, we related measures of awareness of the policy and attention to the media coverage to changes in smoking cessation and use of cessation treatment in order to attempt to disentangle which effects were associated with the policy and which effects with the media attention. Finally, we examined whether there were differential effects for light and moderate-to-heavy smokers.

\section{METHODS}

\section{Sample}

Longitudinal data was used from a four-wave web survey that started in September 2010 and was repeated at approximately 3 month intervals until June 2011, in the Netherlands. This data was originally collected to evaluate the impact of the media campaign about the reimbursement policy. ${ }^{13}$ The study had two survey waves before the start of the media campaign and the reimbursement policy and two survey waves afterwards. See figure 1 for the exact fieldwork periods per survey wave.

A representative sample of smokers aged 18 years and older was recruited through the research firm MarketResponse. In total, 4338 potential respondents were asked to participate, resulting in 2763 respondents (64\%) in wave 1 of the web survey. The follow-up surveys were sent to all respondents who participated in wave 1. At wave 2, 1959 respondents (71\%) took part. At wave 3, 1872 respondents (68\%) participated. Finally, at wave 4, 1609 respondents (58\%) participated. In total, 1216 respondents (44\%) participated in all four waves.

\section{Measurements}

The surveys included questions about background characteristics, smoking characteristics, use of smoking cessation treatment, smoking cessation behaviour, awareness of the reimbursement policy and attention to media coverage. Survey questions were adapted from previous population studies on smoking cessation. ${ }^{18} 19$ The surveys took approximately 8-10 min to complete.

Respondents were asked about their gender, age, education and number of CPD. Age was categorised into 18 years to 39 years, 40 years to 54 years, and 55 years and older. Education was categorised into three levels: low (primary education and lower prevocational secondary education), moderate (middle prevocational secondary education and secondary vocational education) and high (senior general secondary education, (pre-) university education, and higher professional education). Number of CPD was categorised into less than 10 CPD (light smokers) versus 10 or more CPD (moderate-to-heavy smokers).

Awareness of the reimbursement policy was measured by asking respondents 'Is evidence-based smoking cessation treatment reimbursed by all health insurance companies?' Respondents could answer this question with 'Yes' (1) or 'No' (0). Attention to media coverage about the reimbursement policy was measured with the question 'How often have you heard anything in the media about the reimbursement of smoking cessation treatment by health insurance companies in the last 3 months?' Answering categories ranged from 'Never' (0) to 'Often' (3).

Quit attempts were measured by asking whether respondents made any attempt to quit smoking in the last 3 months. Respondents who attempted to quit smoking were asked whether they were smoking again or whether they were still quit. Respondents, who reported to be still quit, were categorised as successful quitters. This measure of quit success is not available for the first survey wave, because the sample contained only current smokers at baseline.

Use of cessation treatment in the past 3 months was measured by asking respondents whether they used any of the following: nicotine replacement therapy (eg, patches or gum), prescription medications (eg, bupropion or nortriptyline), behavioural counselling (eg, by their general practitioner, at a smoking cessation clinic or telephonic coaching) or other cessation treatment (not specified). Respondents who used a combination of nicotine replacement therapy or medications with behavioural counselling or who used only behavioural counselling were all considered eligible for reimbursement (further referred to as 'reimbursed cessation treatment'). Respondents who used nicotine replacement therapy or medications without behavioural counselling are referred to as using 'unreimbursed cessation treatment'.

\section{Analyses}

Analyses were performed with SPSS V.19.0. Data were weighted by age, gender and region to be more representative of the smokers' population in the Netherlands.

Generalised estimating equations (GEE) analyses ${ }^{20} 21$ were performed to assess whether quit attempts, quit success, use of reimbursed treatment and use of unreimbursed treatment changed between the four survey waves. GEE extends multivariate regression analyses to longitudinal analyses of repeated measures. We used binomial variations for all models, the logit link 


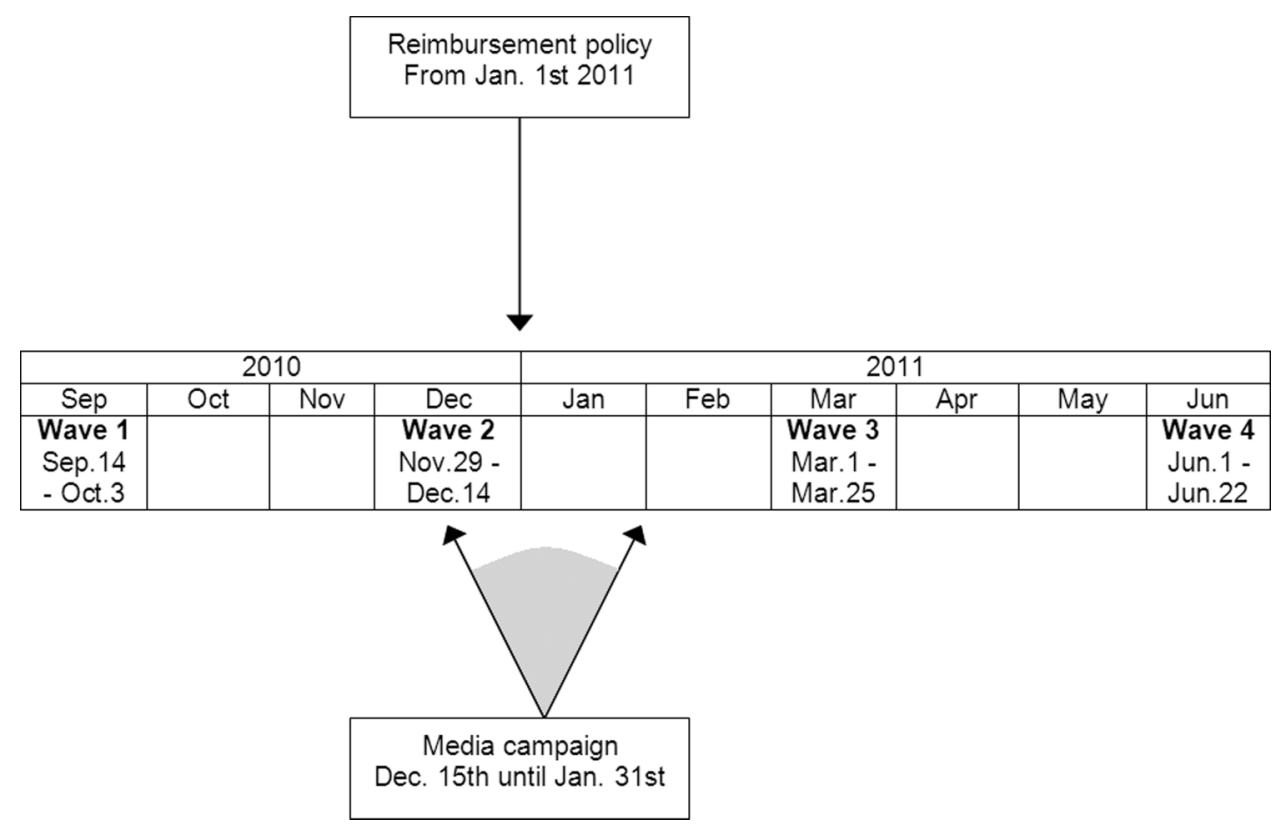

Figure 1 Timeline of September 2010 until June 2011 with survey waves, reimbursement policy and media campaign.

and an unstructured correlation structure. Quit attempts, quit success, use of reimbursed treatment and use of unreimbursed treatment were the dependent variables, as measured at each of the four survey waves. Independent variables were awareness of the reimbursement policy and attention to media coverage about the reimbursement policy, also measured at each wave. Control variables were gender, age group, educational level and number of CPD, as measured at baseline. Survey wave was designated as the repeated measure variable. Separate models were estimated in which the first survey wave was the reference category and in which the second survey wave was the reference category in order to gain more insight into when changes in the outcome measures occurred. Additional models were estimated that also contained interactions of number of CPD (light vs moderate-to-heavy smokers) with survey wave and with the two awareness/attention variables.

\section{RESULTS}

\section{Baseline study sample}

Of the respondents of the baseline survey (unweighted data, not shown in tables), $46 \%$ were male. Most respondents fell in the age group $40-54$ years (42\%) or 55 years and older (39\%). Most respondents had a moderate educational level (39\%), while the low and high educational groups were about equal. There were considerably more moderate-to-heavy smokers (75\%) than light smokers (25\%).

\section{Differential attrition}

Respondents from the current study who were followed up were compared with those who were not followed up to test for differential attrition (unweighted data, not shown in tables). Respondents from the youngest age group (18-39 years old) were significantly less likely to participate in the fourth survey than respondents from the older age groups $\left(\chi^{2}(2)=141.00\right.$, $\mathrm{p}<0.001)$. Furthermore, respondents with a moderate educational level were less likely to participate in the fourth survey than respondents with a low educational level $\left(\chi^{2}(2)=14.32\right.$, $p<0.001)$. These attrition effects for age group and educational level were also statistically significant in the second and third waves of the study and they have become larger with each wave. Respondents who were followed up and who were not followed up did not differ in gender distribution and number of CPD (light vs moderate-to-heavy smokers).

\section{Awareness of policy and attention to media}

As can be seen in table 1 , awareness of the reimbursement policy increased with each wave (all $\mathrm{p}<0.001$ ) from $15 \%$ at wave 1 to $48 \%$ at wave 4 . Attention to media coverage about the reimbursement policy increased until the third wave (all $p<0.001$ ). Between wave 3 and wave 4 there was a small statistically significant decrease $(p=0.030)$ in the attention to media coverage about the reimbursement policy.

\section{Quit attempts}

Of all smokers, $11 \%$ reported to have attempted to quit smoking in the last 3 months at wave 1 and $10 \%$ at wave 2 (table 1). At wave 3, 14\% reported this and at wave 4, 15\%. Only the increase between wave 2 and wave 3 was statistically significant $(\mathrm{p}<0.001)$.

The GEE analysis in table 2 revealed a statistically significant increase in quit attempts at wave $3(\mathrm{OR}=1.33,95 \% \mathrm{CI} 1.13$ to 1.56) and wave $4(\mathrm{OR}=1.47,95 \% \mathrm{CI} 1.24$ to 1.74$)$ compared with wave 1 . When wave 2 was taken as a reference category (not shown in tables), the increase in quit attempts at wave 3 $(\mathrm{OR}=1.31,95 \%$ CI 1.12 to 1.53$)$ and wave $4(\mathrm{OR}=1.45,95 \%$ CI 1.22 to 1.72 ) remained statistically significant. Also shown in table 2 is that attention to media about the reimbursement policy was significantly associated with more quit attempts (OR $=1.18,95 \%$ CI 1.10 to 1.27 ).

Additionally, using wave 1 as the reference category, a statistically significant interaction was found between number of CPD (light vs moderate-to-heavy smokers) and the increase in attempts to quit smoking at the third survey wave $(\mathrm{OR}=1.48,95 \% \mathrm{CI} 1.06$ to 2.08) (table 3). Analyses stratified by number of CPD (not shown in tables) revealed that the increase in attempts to quit smoking between wave 1 and wave 3 was statistically significant only among moderate-to-heavy smokers. Light smokers were significantly more likely to attempt to quit smoking than 
Table 1 Changes in awareness/attention, smoking cessation behaviour and use of cessation treatment between the four survey waves

\begin{tabular}{|c|c|c|c|c|}
\hline & $\begin{array}{l}\text { Wave } 1 \\
\text { September } \\
2010\end{array}$ & $\begin{array}{l}\text { Wave } 2 \\
\text { December } \\
2010\end{array}$ & $\begin{array}{l}\text { Wave } 3 \\
\text { March } 2011\end{array}$ & $\begin{array}{l}\text { Wave } 4 \\
\text { June } 2011\end{array}$ \\
\hline \multicolumn{5}{|l|}{ All smokers } \\
\hline Awareness of the reimbursement policy (\% yes) & 15.4 & $22.6^{* * *}$ & $39.6 * * *$ & $47.5^{* * *}$ \\
\hline Attention to media coverage about the reimbursement policy† (mean, SD) & $0.40(0.78)$ & $0.48(0.83)^{* * *}$ & $0.87(0.98)^{* * *}$ & $0.81(0.96)^{*}$ \\
\hline Smoking cessation attempt (\% yes) & 10.6 & 10.4 & $14.2 * * *$ & 15.0 \\
\hline Smoking cessation success (\% yes) & - & 3.3 & $6.3^{* * *}$ & 8.0 \\
\hline $\begin{array}{l}\text { Use of pharmacological therapy with behavioural counselling or behavioural counselling only } \\
\text { (\% yes) }\end{array}$ & 0.7 & 0.6 & 1.0 & 0.9 \\
\hline Use of pharmacological therapy without behavioural counseling§ (\% yes) & 1.9 & 1.8 & $2.9^{*}$ & 3.6 \\
\hline \multicolumn{5}{|l|}{ All smokers who tried to quit smoking } \\
\hline Smoking cessation success (\% yes) & - & 31.6 & $42.7^{* *}$ & 52.1 \\
\hline $\begin{array}{l}\text { Use of pharmacological therapy with behavioural counselling or behavioural counselling only } \\
\text { (\% yes) }\end{array}$ & 6.6 & 5.6 & 6.8 & 5.6 \\
\hline Use of pharmacological therapy without behavioural counselling (\% yes) & 17.9 & 17.4 & 19.3 & 22.6 \\
\hline
\end{tabular}

moderate-to-heavy smokers at the first and second survey waves, but this difference was no longer statistically significant at the third and fourth survey waves due to an increase in quit attempts among moderate-to-heavy smokers.

\section{Quit success}

Of all wave 1 smokers, 3\% reported to have quit smoking successfully at wave 2 (table 1 ). At wave 3 , this doubled to $6 \%$ and at wave 4 it was $8 \%$. The increase between wave 2 and wave 3

Table 2 Generalised estimating equations analyses of predictors of attempts to quit smoking, quit success, use of reimbursed treatment and use of unreimbursed treatment

\begin{tabular}{|c|c|c|c|c|}
\hline & $\begin{array}{l}\text { Quit attempts } \\
\text { OR ( } 95 \% \mathrm{Cl}) \\
\mathrm{n}=1972\end{array}$ & $\begin{array}{l}\text { Quit success } \\
\text { OR }(95 \% \mathrm{CI}) \\
\mathrm{n}=1746\end{array}$ & $\begin{array}{l}\text { Use of reimbursed } \\
\text { treatment } \\
\text { OR }(95 \% \mathrm{CI}) \\
\mathrm{n}=1900\end{array}$ & $\begin{array}{l}\text { Use of unreimbursed } \\
\text { treatment } \\
\text { OR }(95 \% \mathrm{Cl}) \\
\mathrm{n}=1906\end{array}$ \\
\hline \multicolumn{5}{|l|}{ Gender } \\
\hline Male & 1.00 & 1.00 & 1.00 & 1.00 \\
\hline Female & $1.18(0.98$ to 1.42$)$ & $1.13(0.84$ to 1.53$)$ & $1.03(0.58$ to 1.85$)$ & $0.97(0.67$ to 1.40$)$ \\
\hline \multicolumn{5}{|l|}{ Age group } \\
\hline 18-39 years old & 1.00 & 1.00 & 1.00 & 1.00 \\
\hline $40-54$ years old & 1.25 (0.97 to 1.62$)$ & $1.27(0.82$ to 1.97$)$ & $3.69(1.07 \text { to } 12.77)^{*}$ & $1.28(0.73$ to 2.24$)$ \\
\hline 55 years and older & $0.96(0.73$ to 1.24$)$ & $1.23(0.78$ to 1.92$)$ & $2.97(0.84$ to 10.52$)$ & $0.99(0.55$ to 1.77$)$ \\
\hline \multicolumn{5}{|l|}{ Educational level } \\
\hline Low & 1.00 & 1.00 & 1.00 & 1.00 \\
\hline Moderate & $1.30(1.02 \text { to } 1.65)^{*}$ & $1.26(0.87$ to 1.83$)$ & $1.20(0.55$ to 2.63$)$ & $1.12(0.70$ to 1.79$)$ \\
\hline High & $1.30(1.03 \text { to } 1.64)^{*}$ & $1.02(0.71$ to 1.47$)$ & $1.43(0.70$ to 2.91$)$ & $0.95(0.61$ to 1.47$)$ \\
\hline \multicolumn{5}{|l|}{ Number of cigarettes per day (CPD) } \\
\hline Less than 10 CPD (light smokers) & 1.00 & 1.00 & 1.00 & 1.00 \\
\hline 10 or more CPD (moderate-to-heavy smokers) & $0.64(0.53 \text { to } 0.79)^{* * *}$ & $0.44(0.32 \text { to } 0.59)^{* * *}$ & 0.89 (0.43 to 1.82$)$ & $1.89(1.15 \text { to } 3.09)^{*}$ \\
\hline \multicolumn{5}{|l|}{ Survey wave } \\
\hline 1-September 2010 & 1.00 & - & 1.00 & 1.00 \\
\hline 2-December 2010 & $1.02(0.87$ to 1.19$)$ & 1.00 & $0.83(0.45$ to 1.54$)$ & $0.91(0.64$ to 1.28$)$ \\
\hline 3-March 2011 & $1.33(1.13 \text { to } 1.56)^{* * *}$ & $1.81(1.43 \text { to } 2.28)^{* * *}$ & 0.97 (0.50 to 1.86$)$ & $1.40(0.99$ to 1.97$)$ \\
\hline 4-June 2011 & $1.47(1.24 \text { to } 1.74)^{* * *}$ & $2.19(1.70 \text { to } 2.81)^{* * *}$ & $0.76(0.37$ to 1.56$)$ & $1.43(0.98$ to 2.09$)$ \\
\hline \multicolumn{5}{|l|}{ Awareness of the reimbursement policy } \\
\hline No & 1.00 & 1.00 & 1.00 & 1.00 \\
\hline Yes & $1.08(0.93$ to 1.25$)$ & 1.12 (0.89 to 1.42$)$ & $2.40(1.47 \text { to } 3.95)^{* * *}$ & $1.04(0.76$ to 1.42$)$ \\
\hline $\begin{array}{l}\text { Attention to media coverage about the } \\
\text { reimbursement policyt }\end{array}$ & $1.18(1.10 \text { to } 1.27)^{* * *}$ & $1.20(1.07 \text { to } 1.33)^{* *}$ & $1.20(0.97$ to 1.47$)$ & $1.11(0.94$ to 1.31$)$ \\
\hline
\end{tabular}


Table 3 Generalised estimating equations analyses of predictors of attempts to quit smoking, quit success, use of reimbursed treatment and use of unreimbursed treatment, including interactions

\begin{tabular}{|c|c|c|c|c|}
\hline & $\begin{array}{l}\text { Quit attempts } \\
\text { OR }(95 \% \mathrm{Cl}) \\
\mathrm{n}=1972\end{array}$ & $\begin{array}{l}\text { Quit success } \\
\text { OR }(95 \% \mathrm{Cl}) \\
\mathrm{n}=1746\end{array}$ & $\begin{array}{l}\text { Use of reimbursed } \\
\text { treatment } \\
\text { OR }(95 \% \mathrm{Cl}) \\
\mathrm{n}=1900\end{array}$ & $\begin{array}{l}\text { Use of unreimbursed } \\
\text { treatment } \\
\text { OR }(95 \% \mathrm{Cl}) \mathrm{n}=1906\end{array}$ \\
\hline \multicolumn{5}{|l|}{ Gender } \\
\hline Male & 1.00 & 1.00 & 1.00 & 1.00 \\
\hline Female & $1.18(0.98$ to 1.42$)$ & $1.13(0.84$ to 1.53$)$ & $1.00(0.61$ to 1.63$)$ & 0.95 (0.66 to 1.38 ) \\
\hline \multicolumn{5}{|l|}{ Age group } \\
\hline 18-39 years old & 1.00 & 1.00 & 1.00 & 1.00 \\
\hline $40-54$ years old & 1.26 (0.97 to 1.63$)$ & 1.27 (0.82 to 1.97$)$ & $3.34(1.16 \text { to } 9.57)^{*}$ & 1.33 (0.76 to 2.33 ) \\
\hline 55 years and older & $0.96(0.74$ to 1.25$)$ & 1.23 (0.78 to 1.92$)$ & $2.96(1.03 \text { to } 8.48)^{*}$ & 1.02 (0.57 to 1.82 ) \\
\hline \multicolumn{5}{|l|}{ Educational level } \\
\hline Low & 1.00 & 1.00 & 1.00 & 1.00 \\
\hline Moderate & $1.30(1.02 \text { to } 1.65)^{*}$ & 1.27 (0.88 to 1.85$)$ & 1.23 (0.64 to 2.35$)$ & 1.14 (0.71 to 1.84 ) \\
\hline High & $1.31(1.04 \text { to } 1.65)^{*}$ & 1.03 (0.71 to 1.48$)$ & 1.39 (0.75 to 2.59$)$ & 0.97 (0.62 to 1.50$)$ \\
\hline \multicolumn{5}{|l|}{ Number of cigarettes per day (CPD) } \\
\hline Less than 10 CPD (light smokers) & 1.00 & 1.00 & 1.00 & 1.00 \\
\hline 10 or more CPD (moderate-to-heavy smokers) & $0.52(0.39 \text { to } 0.68)^{* * *}$ & $0.39(0.23 \text { to } 0.65)^{* * *}$ & 0.57 (0.19 to 1.69$)$ & 1.11 (0.54 to 2.28$)$ \\
\hline \multicolumn{5}{|l|}{ Survey wave } \\
\hline 1-September 2010 & 1.00 & - & 1.00 & 1.00 \\
\hline 2-December 2010 & $0.93(0.72$ to 1.20$)$ & 1.00 & 1.12 (0.34 to 3.71$)$ & 0.85 (0.45 to 1.59$)$ \\
\hline 3-March 2011 & 1.02 (0.77 to 1.34$)$ & $1.44(1.04 \text { to } 1.98)^{*}$ & 0.71 (0.17 to 2.93 ) & 0.53 (0.19 to 1.52 ) \\
\hline 4-June 2011 & $1.22(0.92$ to 1.61$)$ & $1.75(1.21 \text { to } 2.52)^{* *}$ & 0.47 (0.09 to 2.44 ) & 0.44 (0.14 to 1.38$)$ \\
\hline \multicolumn{5}{|l|}{ Awareness of the reimbursement policy } \\
\hline No & 1.00 & 1.00 & 1.00 & 1.00 \\
\hline Yes & $1.18(0.88$ to 1.58$)$ & $1.46(1.01 \text { to } 2.11)^{*}$ & $3.91(1.35 \text { to } 11.33)^{*}$ & 0.57 (0.19 to 1.72 ) \\
\hline $\begin{array}{l}\text { Attention to media coverage about the reimbursement } \\
\text { policyt }\end{array}$ & 1.09 (0.96 to 1.24$)$ & $1.19(1.00$ to 1.41$)$ & $0.69(0.37$ to 1.31$)$ & $1.29(0.83$ to 2.00$)$ \\
\hline \multicolumn{5}{|l|}{ Interactions } \\
\hline CPD * survey wave 2 & $1.32(0.93$ to 1.88$)$ & 1.49 (0.90 to 2.48$)$ & $0.63(0.14$ to 2.70$)$ & $1.09(0.52$ to 2.30$)$ \\
\hline $\mathrm{CPD}$ * survey wave 3 & $1.48(1.06 \text { to } 2.08)^{*}$ & 1.51 (0.95 to 2.39$)$ & $1.23(0.25$ to 6.14$)$ & $3.11(1.03 \text { to } 9.46)^{*}$ \\
\hline CPD * survey wave 4 & 1.14 (0.83 to 1.58$)$ & - & $1.46(0.23$ to 9.15$)$ & $3.87(1.15 \text { to } 13.02)^{*}$ \\
\hline CPD * awareness of the reimbursement policy & 0.87 (0.62 to 1.23$)$ & 0.65 (0.40 to 1.04$)$ & $0.76(0.22$ to 2.60$)$ & $1.93(0.61$ to 6.10$)$ \\
\hline $\begin{array}{l}\text { CPD * attention to media coverage about the } \\
\text { reimbursement policy }\end{array}$ & $1.11(0.95$ to 1.30$)$ & 1.01 (0.81 to 1.26$)$ & $2.22(1.11 \text { to } 4.47)^{*}$ & 0.83 (0.52 to 1.34$)$ \\
\hline
\end{tabular}

was statistically significant $(\mathrm{p}<0.001)$. When only taking into account the smokers who attempted to quit smoking, $32 \%$ reported to be still quit at wave 2, 43\% at wave 3 and $52 \%$ at wave 4. Again, the increase between wave 2 and wave 3 was statistically significant $(\mathrm{p}=0.007)$.

Table 2 shows the GEE analysis for all smokers (including those who did not attempt to quit smoking) that confirmed that quit success increased significantly between wave 2 and wave 3 $(\mathrm{OR}=1.81,95 \%$ CI 1.43 to 2.28$)$ and between wave 2 and wave $4(\mathrm{OR}=2.19,95 \% \mathrm{CI} 1.70$ to 2.81$)$. Attention to media about the reimbursement policy was significantly associated with more quit success (OR=1.20, 95\% CI 1.07 to 1.33 ).

An additional GEE analysis (table 3 ) showed that there were no significant interactions of number of CPD with the survey waves or with the awareness/attention variables.

\section{Use of cessation treatment}

Use of reimbursed cessation treatment (pharmacological therapy with behavioural counselling or behavioural counselling only) remained stable at $1 \%$ use or lower of all smokers across waves (table 1). When examining all smokers, use of unreimbursed treatment (pharmacological therapy without behavioural counselling) significantly increased from $2 \%$ at wave 2 to $3 \%$ at wave $3(p=0.025)$. When examining only smokers who attempted to quit smoking, the increase from $17 \%$ to $19 \%$ was not statistically significant.

The GEE analysis in table 2 confirmed that use of reimbursed cessation treatment among all smokers (including those who did not attempt to quit smoking) did not change between waves. This was shown when using wave 1 as a reference category (table 2) and with wave 2 as reference category (not shown in tables). Awareness of the reimbursement policy was significantly associated with more use of reimbursed treatment ( $\mathrm{OR}=2.40,95 \% \mathrm{CI} 1.47$ to 3.95$)$.

Use of unreimbursed cessation treatment among all smokers did not increase when using wave 1 as a reference category (table 2). However, with wave 2 as reference category (not shown in tables), a statistically significant increase in use of unreimbursed treatment between wave 2 and wave $3(\mathrm{OR}=1.55,95 \% \mathrm{CI} 1.10$ to 2.18$)$ and between wave 2 and wave $4(\mathrm{OR}=1.58,95 \%$ CI 1.07 to 2.33$)$ was found. Awareness of the reimbursement policy and attention to media coverage about the policy were not significantly associated with use of unreimbursed cessation treatment.

Additional analyses (table 3), using wave 1 as a reference category, revealed that there was a significant interaction between 
number of CPD (light vs moderate-to-heavy smokers) and attention to media about the reimbursement policy $(\mathrm{OR}=2.22,95 \%$ CI 1.11 to 4.47) on use of reimbursed treatment. Stratified analyses (not shown in tables) showed that attention to media coverage was positively associated with use of reimbursed treatment among moderate-to-heavy smokers, but not among light smokers. There was also a significant interaction of number of CPD with survey wave 3 (OR=3.11, 95\% CI 1.03 to 9.46) and an interaction with survey wave $4(\mathrm{OR}=3.87,95 \%$ CI 1.15 to 13.02). Stratified analyses revealed that use of unreimbursed treatment increased significantly between waves 1 and 3 and between waves 1 and 4 among moderate-to-heavy smokers, but not among light smokers.

\section{DISCUSSION}

Previous research has shown that the introduction of the Dutch national reimbursement policy in 2011 was followed by a statistically significant decrease in smoking prevalence. ${ }^{22}$ Our study reveals that this was due to an increase in quit attempts among moderate-to-heavy smokers and an increase in quit success among all smokers. Our findings further suggest that the increase in smoking cessation can, at least partly, be ascribed to the media attention that accompanied the policy implementation. Attention to media about the reimbursement was significantly associated with more quit attempts and more quit success. Earlier studies reported more use of cessation treatment and methods in 2011: a more than 10-fold increase in telephonic counselling ${ }^{11}$ and a doubling of the number of prescription medications for smoking cessation $^{22}$ in 2011 compared with 2010. The largest increases were found in the second half of 2011 when it was made known by the government that, due to budget cuts, the period of reimbursement would end in December 2011 and more people had already spent their yearly mandatory deductible for their health insurance costs. Our study was restricted to the first 6 months after policy implementation and showed that the percentage of smokers who participated in behavioural counselling did not yet increase in this timeframe, while use of pharmacological therapy without behavioural counselling (not reimbursed) increased among moderate-to-heavy smokers. A possible explanation is that it was not communicated clearly enough that smokers could only get a reimbursement when they also participated in behavioural counselling. Although the use of pharmacological therapy increased, the level of use was still quite low after the implementation $3 \%$ of all smokers used pharmacological therapy without behavioural counselling and $1 \%$ used the combination or behavioural counselling only). This is comparable with findings from the UK, where only $8 \%$ of all smokers use the Stop Smoking Services that are free of charge. ${ }^{4}$

The media campaign that was meant to communicate about the reimbursement policy also showed smokers that it was possible for them to quit smoking. Light smokers may not have immediately thought that they needed cessation treatment to quit smoking, while moderate-to-heavy smokers felt that they needed this support in order to successfully quit when they had heard about cessation treatment in the campaign or in other media. The Dutch media campaign is an example of a 'how-to-quit' campaign. In the international literature, there is not much support for the effectiveness of these kinds of campaigns. ${ }^{23}{ }^{24}$ In general, media campaigns in other countries have shown to be more effective in stimulating quitting when they elicit negative emotions and describe the negative health consequences of smoking ('why-to-quit' campaigns). Possibly, the Dutch campaign was effective because it was combined with the implementation of new tobacco policy. ${ }^{25} 26$
Although the use of reimbursed cessation treatment did not increase, awareness of the reimbursement policy was significantly associated with more use of reimbursed treatment. These results can possibly be explained by reversed causality; respondents who were using reimbursed treatment were, as a result of that, more aware of the reimbursement policy. Furthermore, there was an increase in use of unreimbursed treatment among moderate-to-heavy smokers, but awareness/attention variables were not associated with use of unreimbursed treatment. Therefore, we cannot be sure that the increase in unreimbursed treatment was a consequence of the reimbursement policy and/ or the accompanying media attention.

A limitation of our study is that less than half of respondents participated in all four survey waves. Respondents who were lost to follow-up were younger and more often had a moderate educational level than respondents who did participate in follow-up waves. Therefore, our results may not be fully generalisable to the Dutch population of smokers. Furthermore, we relied on self-reported smoking status to assess quit success. Respondents who reported an attempt to quit and who indicated that they were still quit at the time of the survey were considered successful quitters. However, some of them may have been quit for only a short period of time and may have relapsed soon after the survey.

Our survey design with four survey waves enabled us to separate trends before the interventions from changes after the interventions. However, other events that were not taken into account in this study could also have caused the observed effects. Although New Year's resolutions seem to be a possible alternative explanation for the increase in quit attempts, our data show that the increase was sustained long after the first few months of the year. This strengthens the idea that the reimbursement policy and accompanying media attention were at least partly responsible for the increase in attempts to quit smoking.

Based on the findings from our study, we recommend that countries implement a national reimbursement policy for smoking cessation treatment with accompanying media attention. The media attention is important to increase awareness of the reimbursement policy and can possibly also act as a trigger to stimulate smoking cessation. An intensive mass media campaign such as the one in the Netherlands that reached $80 \%$ of smokers,${ }^{13}$ is recommended. Care should be taken to develop media messages that do not discourage people to quit without the use of cessation treatment. ${ }^{27}$ Media should encourage attempts to quit smoking and the use of evidence-based cessation treatment for those who have more difficulty to quit.

\section{What this paper adds}

- A national reimbursement policy in the Netherlands in 2011 that was accompanied by media attention was followed by an increase in quit attempts among moderate-to-heavy smokers and an increase in quit success among all smokers.

- It seems that the increase in quit attempts and quit success can (partly) be ascribed to the media attention about the reimbursement policy.

Contributors GEN conducted the statistical analyses and drafted the manuscript. She is the guarantor of the paper. MCW and DS contributed to the design of the study and to the statistical analyses. All authors contributed to the interpretation of the data and to the writing of the manuscript. All authors revised the manuscript critically for important intellectual content and read and approved the final manuscript. 
Funding This study was supported by a grant from ZonMw, the Netherlands Organization for Health Research and Development (grant number 50-51300-98-010).

Competing interests None.

Provenance and peer review Not commissioned; externally peer reviewed.

\section{REFERENCES}

1 World Health Organization. WHO Framework Convention on Tobacco Control. Geneva: World Health Organization, 2003.

2 World Health Organization. Guidelines for implementation of Article 14 of the WHO Framework Convention on Tobacco Control (demand reduction measures concerning tobacco dependence and cessation). Geneva: World Health Organization, 2010.

3 Reda AA, Kotz D, Evers SMAA, et al. Healthcare financing systems for increasing the use of tobacco dependence treatment. Cochrane Database Syst Rev 2012; (6):CD004305.

4 West R, May S, West $M$, et al. Performance of English stop smoking services in first 10 years: analysis of service monitoring data. BMJ 2013;347:f4921.

5 Gibson JE, Murray RL, Borland R, et al. The impact of the United Kingdom's national smoking cessation strategy on quit attempts and use of cessation services: Findings from the International Tobacco Control Four Country Survey. Nic Tob Res 2010;12(Suppl 1):64-71.

6 Bauld L, Judge K, Platt S. Assessing the impact of smoking cessation services on reducing health inequalities in England: observational study. Tob Control 2007; 16:400-4.

7 Hiscock R, Murray S, Brose LS, et al. Behavioural therapy for smoking cessation: the effectiveness of different intervention types for disadvantaged and affluent smokers. Addict Behav 2013;38:2787-96.

8 Brose LS, McEwen A, West R. Does it matter who you see to help you stop smoking? Short-term quit rates across specialist stop smoking practitioners in England. Addiction 2012;107:2029-36.

9 Brose LS, West R, McDermott MS, et al. What makes for an effective stop-smoking service? Thorax 2011;66:924-26.

10 Kotz D, Brown J, West R. 'Real-world' effectiveness of smoking cessation treatments: a population study. Addiction Published Online First: 20 December 2013.

11 Willemsen MC, Segaar D, Van Schayck CP. Population impact of reimbursement for smoking cessation: a natural experiment in the Netherlands. Addiction 2013;108:602-4.

12 Thomson S, Osborn R, Squires D, et al. International Profiles of Health Care Systems, 2011. New York: The Commonwealth Fund, 2011. http://www. commonwealthfund.org/ /media/Files/Publications/Fund\%20Report/2011/Nov/ 1562_Squires_Intl_Profiles_2011_11_10.pdf
13 Willems RA, Willemsen MC, Nagelhout GE, et al. Evaluatie van de 'Echt stoppen met roken kan met de juiste hulp' campagne [Evaluation of the 'Really quitting smoking can be done with the right help' campaign]. Maastricht: Maastricht University, 2012.

14 Nagelhout GE, De Korte-de Boer D, Kunst AE, et al. Trends in socioeconomic inequalities in smoking prevalence, consumption, initiation, and cessation between 2001 and 2008 in the Netherlands. Findings from a national population survey. BMC Public Health 2012;12:303.

15 Willems RA, Willemsen MC, Nagelhout GE, et al. Understanding smokers' motivations to use evidence-based smoking cessation aids. Nic Tob Res 2013;15:167-76

16 Dutch Partnership Quit Smoking. Richtlijn behandeling van tabaksverslaving, herziening 2009 [Clinical guideline treatment of tobacco addiction, revision 2009]. The Hague: Partnership Stop met Roken, 2009.

17 Kotz D, Willemsen MC, Brown J, et al. Light smokers are less likely to receive advice to quit from their GP than moderate-to-heavy smokers: a comparison of national survey data from the Netherlands and England. Eur J Gen Pract 2013;19:99-105. Published Online First: 20 March 2013.

18 Fong GT, Cummings M, Borland R, et al. The conceptual framework of the International Tobacco Control (ITC) Policy Evaluation Project. Tob Control 2006;15 (Suppl 3):3-11.

19 Willemsen MC. The new EU cigarette health warnings benefit smokers who want to quit the habit: results from the Dutch Continuous Survey of Smoking Habits. Eur J Public Health 2005;15:389-92.

20 Hardin JW, Hilbe JM. Generalized Estimating Equations. Boca Raton, FL: Chapman \& Hall/CRC, 2003.

21 Liang KY, Zeger SL. Longitudinal data using generalized linear models. Biometrika 1986;73:13-22.

22 Verbiest MEA, Chavannes NH, Crone MR, et al. An increase in primary care prescriptions of stop-smoking medication as a result of health insurance coverage in the Netherlands: population based study. Addiction 2013;108:2183-92.

23 Durkin S, Brennan E, Wakefield M. Mass media campaigns to promote smoking cessation among adults: an integrative review. Tob Control 2012;21:127-38.

24 Hammond D, Wakefield M, Durkin S, et al. Tobacco packaging and mass media campaigns: research needs for articles 11 and 12 of the WHO Framework Convention on Tobacco Control. Nic Tob Res 2013;15:817-31.

25 Thrasher JF, Murukutla N, Pérez-Hernández R, et al. Linking mass media campaigns to pictorial warning labels on cigarette packages: a cross-sectional study to evaluate effects among Mexican smokers. Tob Control 2013;22:e57-65.

26 Chang F-C, Chung C-H, Chuang Y-C, et al. Effect of media campaigns and smoke-free ordinance on public awareness and secondhand smoke exposure in Taiwan. J Health Commun 2011;16:343-58.

27 Chapman S. The inverse impact law of smoking cessation. Lancet 2009; 373:701-3. 